\title{
Learning Curve for Improved Productivity in the South African Construction Industry
}

\author{
Somila Mhini, Nokulunga X. Mashwama, Didibhuku W. Thwala and Clinton O. Aigbavboa
}

Department of Construction Management and Quantity Surveying, University of Johannesburg, Johannesburg, South Africa

Sustainable Human Settlement and Construction Research Centre, Faculty of Engineering and the Built

Environment, University of Johannesburg, Johannesburg, South Africa

\begin{abstract}
The South African construction industry has battled with productivity for years despite being the key contributors to the economy of the country. This paper aims to remedy this problem by introducing the learning curve tool into the South African construction industry. The study sought to deduce the level of awareness of the learning curve and determine the benefits of adopting the learning curve tool in the South African construction industry. The Quantitative Methodology was adopted for this study and participation from construction professionals was obtained through a well-structured questionnaire. A total of 106 questionnaires were sent out and 62 were received back representing a response rate of 58.5\%. The findings revealed that there is a moderate awareness of the learning curve tool in the South African construction industry. Additionally, the findings revealed that the workers would become familiar with their job and sharpen their skills which would result in a higher quality of construction work and the reduction of time taken to complete a task with reduced cost. The adoption of the learning curve tool in the South African construction industry offers a solution to a lasting problem of productivity in the industry. This study will enlighten construction professionals on the concept of the learning curve and the benefits of the learning curve.
\end{abstract}

(c) 2020 The Authors. Published by Budapest University of Technology and Economics \& Diamond Congress Ltd Peer-review under responsibility of the Scientific Committee of the Creative Construction Conference 2020.

Keywords: learning curve, productivity, South African construction industry (SACI), cost

\section{Introduction}

The South African construction industry (SACI) is a vast sector that contributes to the economy of the country, infrastructure and adequate housing [1]. This sector plays a monumental part in the development of the South African economy [2]. Declining labor productivity has been a major issue in the last decade and this has a serious adverse effect on the project's completion and cost [3]. The SACl has its own difficulties that are both internal and external which also impact labour productivity negatively thus the decision-makers in the industry still face the challenge of forecasting and improving productivity [4]. Lack of labour abilities and inexperience of employees lead to poor productivity therefore construction employees and employers need to work together to ensure that the workers become familiar with job processes, instruments and equipment and the working conditions of the construction site to achieve efficient productivity outcomes[3].The basic concept of the learning curve is that the more a particular task is repeated the less time it takes to complete it, furthermore, the learning curve is a practically proven increase in the volume of production based on the prior experience of the worker [5]. The learning curve has been applied over the years in different industries to help companies predict cost implications of the time spent while learning a skill and how it affects productivity and the caliber of outcomes [6]. Hence, this study seeks to the adoption of the learning curve tool into the SACI to improve productivity by investigating 
the circumstances under which the learning curve tool may be adopted into the $\mathrm{SACl}$ and the benefits that may be expected should the learning curve be adopted into the SACl.

\section{The construction industry}

The construction industry one of the biggest sectors in the world in which a building project includes beginning with nothing but an idea and establishing a continuous and durable facility that meets the demands of aesthetics, quality, security and function [7]. This is an industry that operates under the mandate to build and improve the infrastructure of the country thus the progress and success of this industry can be seen in the rate at which the country's projections of development are reached, specifically relating to the development of infrastructure in the country [8]. One of the prominent functions of the construction industry is that it plays a monumental role in the development of a country's asset base because the outputs of construction work are classified as capital or investment goods to the country [1] hence the $\mathrm{SACl}$, much like the construction industries of other countries, has a crucial effect on the economy of the country [9]. The SACl is, by nature, a labor-intensive industry and as such it deploys a significant amount of manpower including semi-skilled and unskilled labor which will, inevitably, impact the level of productivity on construction sites [10]. The variety of labour within the SACl results in productivity being a continuous struggle that the construction industry faces throughout the sector as a whole [11]. This study seeks to expose the possibility of improvement in productivity in the SACl through the adoption of the learning curve.

\section{Declining productivity}

Productivity is the measure of the speed of execution of the job, in whatever field it may be and in building, the production is typically expressed in weight, length or quantity, and the input resource is generally in labor or man-hours costs [12]. Labour productivity is a useful starting point for productivity assessment as it is the single most significant manufacturing factor and represents how effectively labour is combined with other production factors, how many of these other inputs are accessible per employee, and how quickly technically embodied and disembodied change is taking place [13]. Thus labour productivity, by basic definition, is the quantity of goods and services a worker produces in a given amount of time and as such poor labour productivity greatly causes overruns of cost and time in construction projects thus any increase in labour productivity will therefore lead significantly to improving general productivity and improving general output in the industry in terms of quality, cost and time[14]. In many nations, declining labour productivity has been a major issue in the last decade [3] hence the relevance of a study of the learning curve in the construction industry as a declining productivity remedy.

\section{The learning curve}

The learning curve concept was first studied and used in the discipline of psychology by Hermann Ebbinghaus in 1885 and his purpose was to establish the form of the patterns of the people's ability to learn and retain information in his study of memory with the assistance of learning and forgetting curves [15]. Subsequently, T. P. Wright made the first mathematical expression of the learning curve in 1936 when he noted that in the aircraft industry the costs per unit are likely to lessen in a foreseeable way as the employees become more acquainted with the job [16]. Fogliatto \& Anzanello [17] recorded that for production, a formula was deduced by Wright in 1936 to look into the reasons for a decline in the assembly cost of airplanes after repetitions of the task. The learning curve is a mechanism used in the process of projecting future performance in terms of work done by a person or a company and it further links the projected performance to repetitive efforts applied to a task [18]. Jarkas and Horner [19] added that all learning curve models, as many and as seemingly different as they may be, deduce the same fact that an increase in the number of outputs decreases each unit's production inputs such as time, cost and manhours. Furthermore, a decrease in the time or cost necessary to accomplish a task is expected as an individual or a group repeatedly does the task, thus with increasing experience comes somewhat of expertise in the task, making it quicker to execute [5]. The learning curve is presented in a graph format that represents the relationship the effectiveness of the subject and the practice, with relation to productivity thus a concave graph may be expected which is an indication that improvement in productivity is as a result of repetitive work when the practice is plotted on the $x$-axis [20]. 


\section{Circumstances under which the learning curve may be adopted}

According to Malyusz \& Varga [21], forecasting the cost and time it takes to complete repetitive tasks can be done by the adoption of the learning curve theory to the scheduling of activities on-site by using either the unit time method or the cumulative average method which are both effective in the measurement and calculation of activity time for repetitive works. Son, Lee \& Lee [6] documented that the most commonly used model of the learning curve is also recorded to be the first one ever to be used in production and the source of all other models that followed - the Wright model because of its simplicity and accuracy, adding that this learning curve is widely applied in many industries and is not confined to just one. Furthermore, Lee et al [22] observed that the learning curve would be put to its best use in the construction industry because of the repetitive nature of the activities in the construction industry and its use would further improve construction productivity. The learning curve further plays an integral role in contractor claims and a proper examination of this theory should be observed in construction[20]. Wong, Cheung \& Hardcastle [23] examined the adoption of the learning curve theory on the performance of construction contractors to predict productivity and eventually improve it. Brockmann \& Brenziski [24] evaluated the adoption of the learning curve in bridge construction with focus on four specific large freeways in Bangkok, Thailand and in the eventual interpretation of the study the conclusion was made that learning curves may be used in the construction industry as a management tool and that through the activities of construction, firms may get to experience the learning curve effects that contribute to the savings in cost of construction projects. Yap \& Shavarebi [25] explored the ideas of learning in construction to determine ways in which the delivery of construction contracts can be improved especially linked to cost overruns and schedule delays. This study further examines the benefits of adopting the learning curve into the SACI.

\section{Benefits of adopting the learning curve in the construction industry}

Applying the learning curve is most advantageous with planning a budget as the cost of producing the outputs can be calculated, offers the ability to forecast labor hours that may be needed for any kind of work and further plays a monumental role in the decision to distribute the resources of the company effectively [5]. According to Glock et al. [15], the application of the learning curve in industry work may yield benefits that include a more accurate establishment of labor standards, observation of realistic objectives and goals of production, prediction of working time for a task, and forecasting productivity in a specific job. The learning curve, when used effectively, may help to decrease the gross cost of operations associated with the business and the repetition encouraged by the learning curve theory further improves the quality of the services rendered and/or the quality of the outputs produced by those who repeatedly do the task to sharpen skills [5]. The following benefits were outlined in another study of the significance of the learning curve effect [26]:

- Workers become more familiar with the job

- Better team and plant synchronization

- Advanced task planning

- Improved engineering support

- Refined daily management and supervision

- Development of more effective techniques and strategies

- Development of more effective material supply systems

- Definite designs resulting in fewer changes and rework

Gong \& Wang [5] further documented that the experience acquired from spending time applying the principles and technique of a task and the continuation of the process of learning enable the employee to improve in the skill until the time that was required to carry out a task is decreased thus causing a decline in the cost of operations that was initially in place hence in a case where a contractor recruits new staff, determining the candidate's ability to adapt to new work is critical to the appointment process because the candidate's prior experience in similar work leads to a greater chance that the new work will be learned quicker and easier and results in a reduction in training time and cost of training. In a construction site, the application of the learning curve results in the project manager surely having a cost-saving because there 
is a reduction in the labor force needed for work that has been repetitively done over time [21]. The planning of construction projects, monitoring of progress, improvement of productivity and more which lead to further cost savings and control during the administering of construction contracts are the rewards that can be expected as the learning curve theory is applied in the construction industry [27]. The reduction in cost that is attributed to the learning curve effect is a result of a repetitive work in which fewer laborhours are necessary to produce a unit of work as the production of units continues to increase [16].

\section{Methodology}

\subsection{Research area}

The study was executed in the Eastern Cape Province, South Africa. This province was chosen because of its proximity to the researcher and as part of the nine provinces of South Africa with the same regulations and statutory bodies that govern the rest of the SACI then it meets the ideals of this study. It was also an accessible area for the researcher and did not pose distance problems for data collection. Figure 1 shows a map of the Eastern Cape Province.

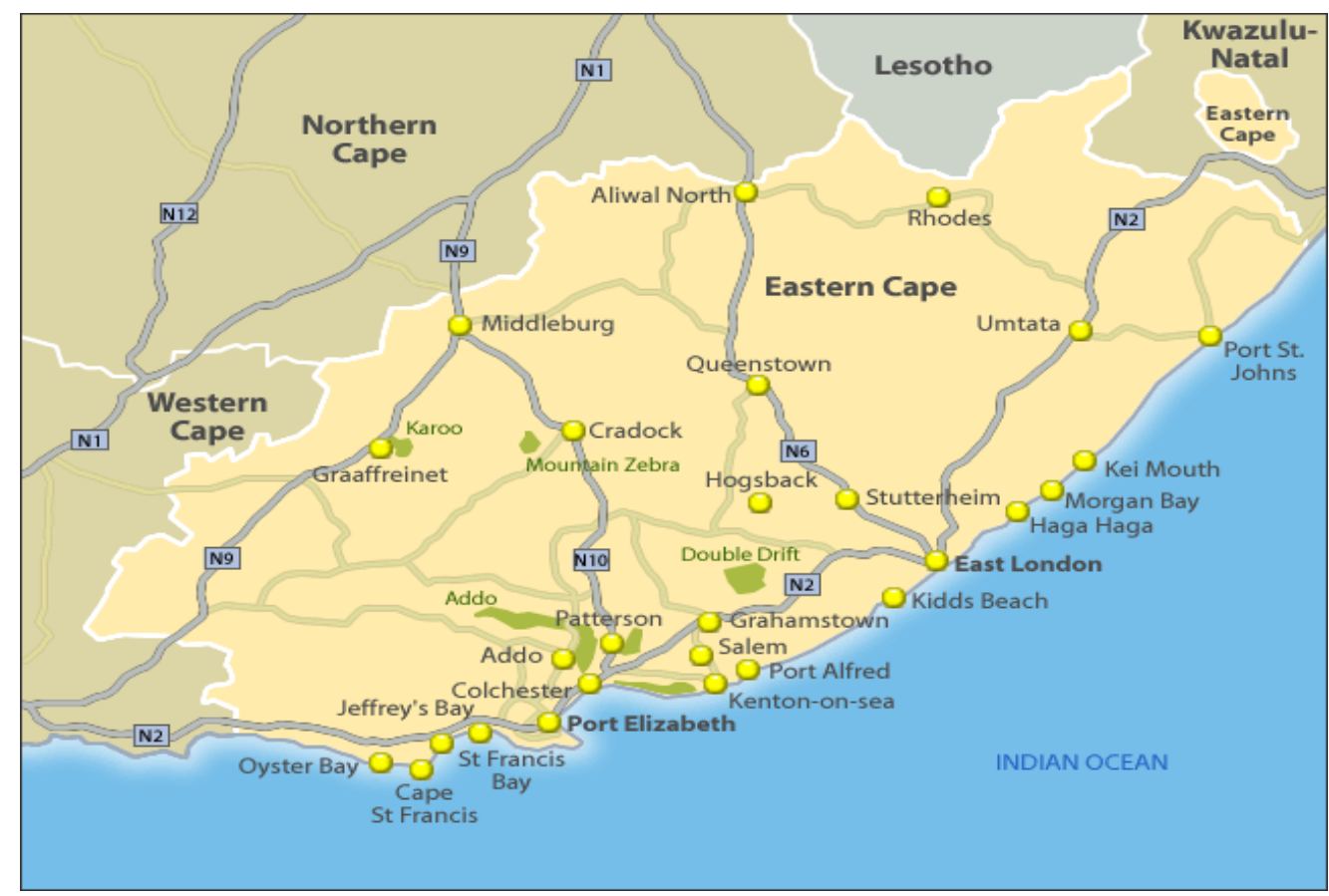

Figure 1 Map of the Eastern Cape Province

Source: http://www.amsterdamcg.nl/map-cape-province-south-africa/

\subsection{Research approach and design}

The Quantitative Methodology was adopted for this study, using the descriptive statistical method to analyze the data received from the respondents. The targeted respondents comprised of construction professionals such as Project Managers, Quantity Surveyors, Engineers, Architects, Health \& Safety Officers, Construction Managers and Contracts Managers who practice the respective professions in the South African construction industry. The random sampling approach was adopted and further, the simple random sampling method was utilized. The research area for this study was the Eastern Cape, South Africa. This was chosen for its easy access and familiarity with the researcher for ease in the collection of data. A structured questionnaire was adopted for data collection. The Likert Scale was used to determine the level of awareness and the degree of agreement of the respondents to the information entailed in the research questionnaire. A total of 106 questionnaires were sent out and 62 were received back representing a response rate of $58.5 \%$.

\subsection{Statistical package for social science}


The MIS was computed electronically with the Statistical Package for the Social Sciences (SPSS) software Version 25 and the items were then further ranked by the researcher with the MIS computed and the Standard Deviation of each item in depreciating order respectively.

\subsection{Point likert scale}

The five-point Likert scale of the agreement was used to determine to what extent the respondents agreed or disagreed with the factors that influence productivity in the $\mathrm{SACl}$, the circumstances under which the learning curve may best be adopted in the $\mathrm{SACl}$ and the benefits of adopting the learning curve tool in the SACl. The Likert Scale of the agreement includes the ranges: 1 . = Strongly disagree (SD); 2. = Disagree (D); 3. $=$ Neutral $(\mathrm{N}) ; 4 . \quad=$ Agree $(\mathrm{A}) ; 5 .=$ Strongly agree $(\mathrm{SA})$

\subsection{Computation of the mean item score (MIS)}

The computation of the relative mean item score (MIS) was calculated from the total of all weighted responses and then relating it to the total responses. This was based on the principle that respondents' scores on all the selected criteria, considered together, are the empirically determined indices of relative importance. The index of MIS of a factor is the sum of the respondents' actual scores (on the 5-point scale) given by all the respondents as a proportion of the sum of all maximum possible scores on the 5-point scale that all the respondents could give to that criterion. A weighting was assigned to each response ranging from one to five for the responses of 'strongly disagree' to 'strongly agree' and the same was assigned to the other responses. This is expressed mathematically below. The mean item score (MIS) was calculated for each item as follows;

$$
M I S=\frac{1 n 1+2 n 2+3 n 3+4 n 4+5 n 5}{\sum N}
$$

Where;

$\mathrm{n} 1=\quad$ Number of respondents for extremely unlikely or strongly disagree;

$\mathrm{n} 2=$ Number of respondents for unlikely or disagree;

$\mathrm{n} 3=$ Number of respondents for neutral;

$\mathrm{n} 4=$ Number of respondents for likely or agree;

$\mathrm{n} 5=\quad$ Number of respondents for extremely likely or strongly agree;

$\mathrm{N}=$ Total number of respondents

After mathematical computations, the criteria are then ranked in descending order of their mean item score (from the highest to the lowest). A mean value of 3.50 or more was deemed to be significant to the study.

\section{Findings}

8.1. Findings - The circumstances under which the learning curve tool may best be adopted in the SACI

Table 1 reveals the responses of the respondents to the circumstances under which the learning curve tool may best be adopted in the SACl, calculated together using the MIS method and thus assigned a ranking of the concepts in descending order. The findings showed that out of the circumstances listed, when 'scheduling and planning for construction activities' ranked first, with a mean score of 4.10 and a standard deviation of 0.900; when 'erecting High-rise multiple story buildings' ranked second, with a mean score of 4.05 and a standard deviation of 1.015; when 'forecasting the cost of operations on-site' ranked third, with a mean score of 4.00 and a standard deviation of 0.789 ; when 'construction designs have repetitive measurements for different floors' ranked fourth, with a mean score of 3.98 and a standard deviation of 0.983; and when 'an unchanged construction crew works on foundations of identical measurements' ranked fifth, with a mean score of 3.97 and a standard deviation of 0.829, which comprised the top-ranked circumstances under which the learning curve tool may best be adopted in the SACl. Furthermore, the least ranked circumstances under which the learning curve tool may best be adopted in the SACl include: when 'there's an estimated period of one week between similar projects' which ranked twelve, with a mean score 
of 3.65 and a standard deviation of 0.960; when 'mechanization is highly incorporated in the task' which ranked thirteen, with a mean score of 3.60 and a standard deviation of 0.896; when 'workers are aware of the learning curve theory' which ranked fourteen, with a mean score of 3.58 and a standard deviation of 1.033; when 'the work proceeds from harder to easier tasks' which ranked fifteen, with a mean score of 3.48 and a standard deviation of 0.987; and when 'there's an estimated period of one month between similar projects' which was least ranked sixteen, with a mean score of 3.45 and a standard deviation of 1.066.

Table 1: The circumstances under which the learning curve tool may best be adopted in the SACl

\begin{tabular}{|c|c|c|c|}
\hline The learning curve tool is best adopted in the construction industry when... & $\overline{\mathbf{x}}$ & $\sigma \mathrm{X}$ & $\mathbf{R}$ \\
\hline ...scheduling and planning for construction activities. & 4,1 & 0,9 & 1 \\
\hline ...erecting High-rise multiple story buildings. & 4,05 & 1,015 & 2 \\
\hline ...forecasting the cost of operations on site. & 4 & 0,789 & 3 \\
\hline ...construction designs have repetitive measurements on different floors. & 3,98 & 0,983 & 4 \\
\hline measurements. & 3,97 & 0,829 & 5 \\
\hline ...the drawings and specifications are crucial to the execution of the task. & 3,89 & 0,994 & 6 \\
\hline ...the same project manager for different jobs with similar specifications. & 3,84 & 0,961 & 7 \\
\hline ...similar projects are constructed in the same geographical location. & 3,81 & 1,006 & 8 \\
\hline ....an unchanged construction crew works on identical structures of the same size. & 3,77 & 0,965 & 9 \\
\hline ...the working space is not overcrowded. & 3,74 & 0,867 & 10 \\
\hline ...the task is not a one-man job. & 3,74 & 1,07 & 10 \\
\hline ...the repetitive task is complex and difficult. & 3,66 & 0,867 & 11 \\
\hline ...there are no interruptions and delays in the work. & 3,66 & 0,991 & 11 \\
\hline ...there's an estimated period of one week between similar projects. & 3,65 & 0,96 & 12 \\
\hline ...mechanization is highly incorporated in the task. & 3,6 & 0,896 & 13 \\
\hline ...workers are aware of the learning curve theory. & 3,58 & 1,033 & 14 \\
\hline ....the work proceeds from harder to easier tasks. & 3,48 & 0,987 & 15 \\
\hline ...there's an estimated period of one month between similar projects. & 3,45 & 1,066 & 16 \\
\hline
\end{tabular}

\subsection{Findings - The benefits of adopting the learning curve tool}

Table 2 reveals the responses of the respondents to the benefits of adopting the learning curve tool in the $\mathrm{SACl}$, calculated together using the MIS method and thus assigned a ranking of the concepts in descending order. The findings revealed that 'Development of more effective techniques and strategies' ranked first, with a mean score of 4.24 and a standard deviation of 0.740 ; 'Workers become more familiar with the job' ranked second, with a mean score of 4.19 and a standard deviation of 0.827; 'Sharpening the skills/craft of employees' ranked third, with a mean score of 4.19 and a standard deviation of 0.865 ; 'Higher quality construction work, structures and buildings' and 'Reduction of time taken to complete repetitive task' both ranked fourth, with a mean score of 4.13 and a standard deviation of 0.839 respectively; and 'Better team and plant synchronization' ranked fifth, with a mean score of 4.13 and a standard deviation of 0.859 . Moreover, the least ranked benefits of adopting the learning curve in the SACl included: 'Reduction in training time and cost for new staff' which ranked twelfth, with a mean score of 3.95 and a standard deviation of 0.798; 'Cost saving due to decrease in no. of laborers' which ranked thirteenth, with a mean score of 3.94 and a standard deviation of 1.006; 'Easier recruitment process for new staff, tenderers and subcontractors' which ranked fourteenth, with a mean score of 3.87 and a standard deviation of 0.932; 'Definite designs resulting in less changes and rework' which ranked fifteenth, with a mean score of 3.84 and a standard deviation of 0.961 ; and 'Improved engineering support' which ranked the least as sixteenth, with a mean score of 3.69 and a standard deviation of 1.049 . 
Table 2: The benefits of adopting the learning curve tool in the SACI

\begin{tabular}{lrrr}
\hline Benefits of the Learning Curve Tool & $\overline{\mathbf{x}}$ & $\boldsymbol{\sigma X}$ & $\mathbf{R}$ \\
\hline Development of more effective techniques and strategies. & 4,24 & 0,74 & 1 \\
Workers become more familiar with the job. & 4,19 & 0,827 & 2 \\
Sharpening the skills/craft of employees. & 4,19 & 0,865 & 2 \\
Higher quality construction work, structures and buildings. & 4,13 & 0,839 & 3 \\
Reduction of time taken to complete a repetitive task. & 4,13 & 0,832 & 3 \\
Better team and plant synchronization. & 4,13 & 0,859 & 3 \\
More accurate scheduling for construction activities. & 4,1 & 0,824 & 4 \\
Advanced task planning. & 4,08 & 0,836 & 5 \\
Better monitoring of progress. & 4,06 & 0,866 & 6 \\
Refined daily management and supervision. & 4,06 & 0,862 & 6 \\
Less number of laborers required for repetitive tasks. & 4,03 & 0,809 & 7 \\
More accurate estimates for the construction budget (monetary and labor hours). & 4,03 & 0,829 & 7 \\
Development of more effective material supply systems. & 4,02 & 0,896 & 8 \\
Reduction in training time and cost for new staff. & 3,95 & 0,798 & 9 \\
Cost-saving due to a decrease in no. of laborers. & 3,94 & 1,006 & 10 \\
The easier recruitment process for new staff, tenderers and subcontractors. & 3,87 & 0,932 & 11 \\
Definite designs resulting in fewer changes and rework. & 3,84 & 0,961 & 12 \\
Improved engineering support. & 3,69 & 1,049 & 13 \\
\hline & & & \\
\hline
\end{tabular}

\section{Conclusion}

The reviewed literature revealed that there is a vast well of knowledge that has been discovered about the learning curve tool ever since the investigation into the concept commenced. That knowledge has not yet spread into the $\mathrm{SACl}$ thus rendering the industry at a loss of the benefits that could be utilized in it from the learning curve tool. The practices of the $\mathrm{SACl}$ are recognized to be conducive to the adoption of the learning curve tool to improve productivity. Though there are measures in place that are designed to help improve productivity in the $\mathrm{SACl}$, here is a tool that has been examined for its productivity-improving benefits and aligned to the activities and operations in the SACI with the sampled construction professionals supporting the ideas around it. The study results showed that when scheduling and planning for construction activities, when erecting high-rise multiple story buildings, when forecasting the cost of operations on site, when construction designs have repetitive measurements on different floors and when an unchanged construction crew works on foundations of identical measurements were considered the most viable conditions under which the learning curve could be adopted into the South African construction industry while the most esteemed benefits of adopting the learning curve tool, as revealed in this study, were the development of more effective techniques and strategies, workers become more familiar with the job, sharpening the skills/craft of employees, higher quality construction work, structures and buildings and reduction of time taken to complete a repetitive task. In agreement with the data collected, it is safe to conclude that the study has enlightened the construction professionals who participated in the study of the learning curve tool and may successfully be adopted into the SACl for the improvement of productivity. The study has met all its objectives and answered all the research questions that were set out for this investigation.

\section{Acknowledgments}

Heartfelt gratitude and acknowledgment to the National Research Forum (NRF) Thuthuka grant for the support and encouragement throughout the compilation of this work. 


\section{References}

[1] Mahamid, I. (2013). Contractors' perspective toward factors affecting labor productivity in building construction. Engineering, Construction and Architectural Management, 20(5), 446-460, ISSN: 0969-9988. Available from: https://doi.org/10.1108/ECAM-082011-0074

[2] Bowen, P., Pearl, R. \& Akintoye, A. (2007). Professional ethics in the South African Construction Industry. Building Research and Information, 35(2): 189-205. Available from: https://doi.org/10.1080/09613210600980267.

[3] Porntepkasemsant, P. \& Charoenpornpattana, S. (2015). Factor Affecting Construction Labor Productivity in Thailand. 2015 International Conference on Industrial Engineering and Operations Management, 1-6. Available from: https://doi.org/10.1109/IEOM.2015.7093749 .

[4] Karunarathna, D.M.T.G.N.M. \& Siriwardana, C.S.A. (2018). A Tool to Assess Construction Worker Productivity. 2018 Moratuwa Engineering Research Conference, 1-6. Available from: https://doi.org/10.1109/MERCon.2018.8421909 .

[5] Gong, H. \& Wang, M. (2010). Learning Curve: Principle, Application and Limitation. 2010 International Conference on E-Business and E-Government, 1840-1843. Available from: https://doi.org/10.1109/ICEE.2010.465

[6] Son, K., Lee, W. \& Lee, K. (2018). Prediction of the Learning Curves of 2 Dental CAD Software Programs. The Journal of Prosthetic Dentistry, 121:1, 95-100. Available from: https://doi.org/10.1016/j.prosdent.2018.01.004

[7] Tucker, R. L. (1986). Management of Construction Productivity. Journal of Management in Engineering, 2(3): 148-156. Available from: https://doi.org/10.1061/(ASCE)9742-597X(1986)2:3(148) .

[8] Tshikhudo, L. M. (2016). Development of Construction Small, Medium and Micro Enterprise. MTech (Construction Management): University of Johannesburg. Available from: http://hdl.handle.net/10210/72836

[9] Oshungade, O. O. \& Kruger, D. (2017). A Comparative Study of Causes and Effects of Project Delays and Disruptions in Construction Projects in the South African Construction Industry. Journal Article. Available from: http://hdl.handle.net/10210/246292

[10] Moswane, D. G. (2018). An Assessment of the Factors Affecting Labour Productivity on Construction Projects in Northwest Province South Africa. MTech (Construction Management): University of Johannesburg. Available from: http://hdl.handle.net/10210/280149

[11] Sveikauskas, L., Rowe, S. \& Mildenberger, J. D. (2018). Measuring Productivity Growth in Construction: 141 Monthly Labour Review. Available from: https://www.bls.gov/opub/mlr/2018/article/pdf/measuring-productivity-growth-in-construction.pdf

[12] Hattingh, E., van Waveren, C. C. \& Chan, K.-Y. (2019). A Learning Curve Theory Perspective on Projects - Ranking the Key Determinants to Improve Project Efficiency. South African Journal of Industrial Engineering, 30(1): 37-53. Available from: http://sajie.journals.ac.za/pub/article/view/1886

[13] Chia, F. C., Skitmore, M., Runeson, G. \& Bridge, A. (2014). Economic development and construction productivity in Malaysia, Construction Management and Economics, 32(9): 874-887. Available from: https://doi.org/10.1080/01446193.2014.938086

[14] De Silva, N., Darmicka, R., \& Elmo, F. (2014). Impact of foreign workforce on productivity in foreign-funded infrastructure projects. Journal of Financial Management of Property and Construction, 19(2), 168-183. Available from: https://doi.org/10.1108/JFMPC-01-2013-0002

[15] Glock, C.H., et al. (2018). Applications of learning curves in production and operations management: A systematic literature review. Computers \& Industrial Engineering, 131: 422-441. Available from: https://doi.org/10.1016/j.cie.2018.10.030

[16] Wideman, M. R. (1994). Applying Resource Loading, Production \& Learning Curves to Construction: A Pragmatic Approach. Canadian Journal of Civil Engineering, 21: 939-953. Available from: https://doi.org/10.1139/194-100

[17] Fogliatto, F. S. \& Anzanello, M. J. (2011). Learning Curves: The State of the Art and Research Directions. Learning Curves: Theory, Models and Applications- Chapter 1. Boca Raton: CRC Press, Taylor \& Francis Group. ISBN - 13: 978-1-4398-0740-8 (eBook - PDF)

[18] Globerson, S. (1980) Introducing the repetition pattern of a task into its learning curve. International Journal of Production Research, 18:2, 143-152. Available from: https://doi.org/10.1080/00207548008919656

[19] Jarkas, A. \& Horner, M. (2011). Revisiting the applicability of learning curve theory to formwork labor productivity. Construction Management and Economics Journal, 29:5, 483-493. Available from: https://doi.org/10.1080/01446193.2011.562911

[20] Thomas, H. R. (2009). Construction Learning Curves. Practice Periodical on Structural Design and Construction, 14(1): 14-20. Available from: https://doi.org/10.1061/(ASCE)1084-0680(2009)14:1(14)

[21] Mályusz, L. \& Varga, A. (2016). An Estimation of the Learning Curve Effect on Project Scheduling with Working Days Calculations. Periodica Polytechnica Architecture, 47(2): 104-109. Available from: https://doi.org/10.3311/PPar.10387

[22] Lee, B. et al. (2015). Influence Factors of the Learning Curve Effect in High-rise Building Constructions. Journal of Construction Engineering and Management, 141(8): 04015019(1-11). Available from: https://doi.org/10.1061/(ASCE)CO.1943-7862.0000997

[23] Wong, P. S. P., Cheung, S. O. \& Hardcastle, C. (2007). Embodying Learning Effect in Performance Prediction. Journal of Construction Engineering and Management, 133(6): 474-482. Available from: https://doi.org/10.1061/(ASCE)0733-9364(2007)133:6(474)

[24] Brockmann, C. \& Brezinski, H. (2015). Experience curve effects in bridge construction. Procedia Economics and Finance, 21: 563 570. Available from: https://doi.org/10.1016/S2212-5671(15)00213-0

[25] Yap, J. B. H. \& Shavarebi, K. (2019): Enhancing Project Delivery Performances in Construction Through Experiential Learning and Personal Constructs: Competency Development. International Journal of Construction Management, 1-17. Available from: https://doi.org/10.1080/15623599.2019.1629864

[26] Thomas, H. R., Mathews, C. T. \& Ward, J. G. (1986). Learning Curve Models of Construction Productivity. Journal of Construction Engineering and Management, 112(2): 245-258. Available from: https://doi.org/10.1061/(ASCE)0733-9364(1986)112:2(245)

[27] Srour, F. J., Kiomjian, D. \& Srour, I. M. (2015). Learning Curves in Construction: A Critical Review and New Model. Journal of Construction Engineering and Management, 142(4): 06015004(1-5). Available from: https://doi.org/10.1061/(ASCE)CO.19437862.0001096 